\title{
Entre las luchas pasadas y las presentes Antecedentes, surgimiento y consolidación de la etnohistoria andina chilena
}

\section{( Carlos María Chiappe}

Universidad Católica del Norte, Instituto de Arqueología y Antropología, San Pedro de Atacama, Chile Identificador Digital: http://orcid.org/oooo-0002-1760-6004

Correo electrónico: carlos.chiappe@ucn.cl

Tesis de doctorado, Facultad de Filosofía y Letras, Universidad de Buenos Aires Director: Dr. Carlos Eduardo Zanolli Fecha de defensa de tesis: 17 de mayo de 2018

La investigación analizó el desarrollo de la etnohistoria andina chilena entre 1970 y 1989 -es decir, durante la dictadura pinochetista - tomando en cuenta los antecedentes, surgimiento y consolidación. Los objetivos fueron fijados luego de establecer una orientación lo suficientemente amplia, que permitiese contener los desplazamientos lógicos que conlleva cualquier investigación. Estos fueron:

1. Analizar los antecedentes, surgimiento y desarrollo de la etnohistoria andina chilena, a) dando cuenta de las evoluciones teórico-metodológicas y de los cambios en los marcos espacio-temporales y temáticos; y b) reconociendo los principales actores (investigadores e instituciones), medios de difusión (eventos y publicaciones) y proyectos.

2. Analizar la incidencia del contexto sociopolítico por medio del estudio de los procesos sociales y de las políticas gubernamentales que afectaron el campo académico-científico en general y la etnohistoria andina chilena en particular.

Las herramientas teórico-metodológicas consistieron en el abordaje biográfico, de redes y los estudios sobre ideas. Las fuentes de información fueron la investigación documental y bibliográfica, las entrevistas y la observación participante.

La investigación planteó y discutió cinco tesis sobre el problema en estudio:
Tesis $1^{\underline{a}}$, referida a los factores intervinientes en el surgimiento de la etnohistoria andina chilena

Se propuso que este surgimiento, ocurrido a inicios de 1970, estuvo relacionado con:

i) El llamado boom de la etnohistoria andina. Durante esta etapa, a la vez que se lograba afianzar lo andino como una "civilización" con igual valía que la del área mesoamericana, se empezó a investigar por fuera de las regiones ubicadas en el actual Perú y más allá de la temática incaica. En adelante, la etnohistoria empezó a pensar lo regional no necesariamente en conexión con los Andes centrales, más allá de que se utilizasen o se discutiesen modelos teóricos pensados para el Perú.

ii) El desarrollo de los estudios andinos chilenos, entre los que se observan dos orientaciones: la geopolítica (1850-1930) y la desarrollista (1950-1970). Estas expresaron diferentes articulaciones entre ciencia y políticas estatales y promovieron discusiones sobre el sujeto indígena que fueron luego retomadas por la etnohistoria mediante una forma de producción de conocimiento original basada en la interdisciplina.

iii) Las relaciones establecidas entre la arqueología, la antropología social y la historiografía, como expresión local de un movimiento más general que se dio a partir de la segunda mitad del siglo XX en todo el mundo. Se propuso que, en el momento de su surgimiento, se habían generado fuertes vasos comunicantes interdisciplinares, lo cual habría facilitado el desarrollo de la etnohistoria.

iv) El contexto sociopolítico chileno, en el que existía un creciente interés por conocer las características 
étnicas de las poblaciones indígenas afectadas por la reforma agraria (1962-1973), a la par que se promovían procesos de reemergencia étnica.

v) La modernización dependiente de las ciencias sociales latinoamericanas, que promovió la rápida ampliación del campo académico-científico chileno entre 1950 y 1970, habilitó entonces un proceso de institucionalización que generó importantes recursos humanos y materiales a lo largo del país, los cuales fueron indispensables para el desarrollo de la etnohistoria.

Tesis $\mathbf{2}^{\mathrm{a}}$, referida a los criterios de identificación de los investigadores pioneros (ca. 1970)

El tipo de etnohistoria practicada en Chile en la década de 1980, que en esta tesis se caracteriza como de consolidación y a la que, en el plano internacional, se denomina "nueva etnohistoria", presentó como características básicas: 1 ) un sujeto de estudio consistente en el llamado mundo indígena, ya sea en la época anterior o posterior a la conquista y tomando en cuenta las relaciones establecidas con otros colectivos sociales, indígenas o no; 2) el abordaje interdisciplinario, ya sea de un mismo investigador que incorpora fuentes de información históricas, arqueológicas y etnográficas o de un equipo de investigación con especialistas de distintas disciplinas; 3) el uso de fuentes documentales novedosas, abordadas con enfoque antropológico; 4) una impronta regional en las investigaciones; y 5) un intento de superar las visiones dicotómicas y de focalizar, en cambio, en los entramados de sistemas que se produjeron durante la colonia. Se propuso que, a partir de dichas perspectivas, es posible determinar cuáles de las investigaciones pioneras de la década de 1970 constituyeron antecedentes de las investigaciones de la década de 1980.

\section{Tesis $3^{\mathrm{a}}$, referida al período de consolidación de la} etnohistoria andina en Chile

La década de 1980 marcó el momento de consolidación de la etnohistoria en Chile. Esto sucedió en el marco de un interés creciente por dar cuenta de la variabilidad de lo andino y antes de ponerse en cuestión las limitaciones del paradigma andinista, lo que ocurriría a partir de 1990. En el campo local, la consolidación de la etnohistoria se evidenció en la formación de equipos relacionados con determinadas instituciones, encabezados por investigadores destacados, conformados por profesionales de distintas disciplinas y financiados mediante fondos públicos. Se propuso que las investigaciones desarrolladas por estos equipos estuvieron organizadas alrededor de la idea de estrategias de supervivencia cuyo análisis constituyó el eje central de la práctica etnohistórica en el momento de su consolidación.

\section{Tesis $4^{\mathrm{a}}$, sobre los investigadores "nodos"}

La consolidación de la etnohistoria andina en Chile requirió de individuos preparados para articular la creación de espacios y equipos a nivel local con su visibilización en el plano internacional, para lo cual debieron ser capaces, tanto de acceder a los recursos institucionales disponibles, como de emplear estratégicamente vínculos formales e informales. Al articular sus relaciones para la formación de equipos de trabajo, la gestión de eventos académicos y la participación en instancias trasnacionales de legitimación de la producción, estos investigadores se constituyeron en nodos centrales de redes compuestas por académicos locales y extranjeros. Los investigadores-nodo contribuyeron, de este modo, a una redefinición de las prácticas etnohistóricas por medio de la incorporación de nuevos enfoques teórico-metodológicos y mediante de la gestión de espacios institucionales.

\section{Tesis $5^{\mathrm{a}}$, sobre el papel político de la etnohistoria}

El trabajo de los etnohistoriadores presentó un carácter político, en tanto aquellos:

i) Realizaron una puesta en valor de las variadas estrategias adoptadas por los pueblos originarios para aprovechar las coyunturas planteadas por los diferentes escenarios históricos, lo cual situó a los indígenas como actores relevantes de la historia del país.

ii) Configuraron a la etnohistoria como un espacio distintivo en el campo académico nacional por medio del abordaje de la historicidad de un sujeto particular -el indígena-que había sido negado por la historiografía dominante como integrante de la nación por pretenderse esta homogénea.

iii) Generaron un conocimiento crítico enmarcado en el contexto dictatorial, pasible de ser apropiado y reelaborado por los pueblos originarios en la lucha para la consecución de sus autonomías político-culturales.

Las conclusiones de la tesis repasan las principales características del campo etnohistórico chileno en los momentos de surgimiento y consolidación, en tanto enmarcan debidamente el proceso local con el desarrollo global de la etnohistoria andina. Además, realizan algunas consideraciones de tipo teórico-metodológico e incorporan planteamientos de tono general sobre las características de la etnohistoria en relación con la historiografía y antropología 
hegemónicas. Finalmente, se trazan posibles líneas inquisitivas sobre el tema en estudio para desarrollar en el futuro. Sobre este último particular, la tesis ha servido de base para implementar en la actualidad un proyecto de investigación denominado "Producción, coproducción, apropiación y reelaboración del conocimiento histórico-académico por parte de los pueblos indígenas del Norte de Chile" (Universidad Católica del Norte, Chile). 
